\title{
Psychedelic mushrooms in the USA: Knowledge, patterns of use and association with health outcomes
}

\author{
Matzopoulos $\mathrm{R},{ }^{1,2}$ Morlock $\mathrm{R},{ }^{3}$ Morlock $\mathrm{A},{ }^{4}$ Lerer $\mathrm{B}^{5}$, Lerer $\mathrm{L}^{6}$
}

1. Burden of Disease Research Unit, South African Medical Research Council, Cape Town, South Africa

2. School of Public Health and Family Medicine, Faculty of Health Sciences, University of Cape Town, South Africa

3. YourCareChoice, Ann Arbor, Michigan, United States of America

4. Acumen Health Research Institute, Ann Arbor, Michigan, United States of America

5. Biological Psychiatry Laboratory and Hadassah BrainLabs, Hadassah - Hebrew University Medical Center, Jerusalem, Israel

6. Back of the Yard Algae Sciences - Parow Entheobiosciences, Chicago, Illinois, United States of America

\begin{abstract}
Introduction: Popular media coverage, including of recent positive late stage clinical trials in depression and PTSD, and decriminalization initiatives, are transforming the public perception of psychedelics. However, little is known about levels of knowledge and personal use of psychedelic mushroom(s) (PM) among American adults.
\end{abstract}

Methods: We examined PM use and various measures of health status, quality of life and selfreported mental health outcome measures obtained through a national on-line, cross-sectional survey of adults with a demographic composition representative of the US adult population by region, gender, age, and race (weighted $\mathrm{N}=251,297,495$ ) from November 2020-March 2021.

Results: General mental health and well-being was a popular reason for PM use (63.6\%). PM users were less likely to be overweight than non-users, but overall quality of life (VR-12) was lower for mental health (39.5 vs 45.5). PM users reported significantly higher levels of anxiety (GAD-7 scores of 9.6 vs 5.9 ) and depression (PHQ-9 scores of 11.2 vs 6.8 ). They were less likely to have health insurance $[\mathrm{OR}=0.50(0.35-0.72)]$, but reported significantly more healthcare services utilization.

Discussion and Conclusions: There is a mismatch between our findings of an association between PM use and poor mental health outcomes, and current discourse on the positive health benefits of PM consumption. A significant number of Americans are already "self medicating" with PM and further research to understand the role of anecdotal knowledge and pseudoscientific information in PM uptake. There is an urgent need for a PM use-related national harm reduction strategy. 
It is made available under a CC-BY-NC-ND 4.0 International license .

\section{INTRODUCTION}

Psychedelics (serotonergic hallucinogens) have powerful and generally predictable psychoactive effects, influencing perception, mood and cognition (1). Following a long hiatus globally linked to restrictive legislative policies, the past decade has seen an exceptional resurgence of research into the therapeutic potential of psychedelics, particularly psilocybin (2), for the treatment of conditions including depression, post-traumatic stress disorder (PTSD) and addiction (3)(4)(5). By December 2020, 70 clinical studies were registered on clinicaltrials.gov, of which $70 \%$ were still underway. There is also growing evidence of the potential utility of psychedelics for a range of mental health conditions, pain and neurodegenerative disorders $(6)(7)(8)(9)$.

Biomedical research interest in psychedelics, has been mirrored in a wave of largely positive public discourse (10). In May 2021 the New York Times led a front page article heralding a "psychedelic revolution" (11) following publication of extremely promising Phase 3 clinical trial results on MDMAassisted psychotherapy for PTSD (12). There is also renewed interest in psychedelics in popular culture, from psychedelic content on streaming media such as the Netflix series The goop Lab (13) and Vice Media's Hamilton's Pharmacopeia, and increasing popularity in social media apps such as Clubhouse, which posts weekly live podcasts including weekly content such as The Psychedelic News Hour (14). A successful psilocybin legalization initiative in Oregon, possible impending psychedelics legalization in California and psychedelic fungi and plant possession decriminalisation ordinances in several cities across the US (including Ann Arbor, Washington DC and Oakland) are driving public policy in the direction of a future recognition of psychedelics as potentially useful for health and wellness. There is however some concern that this wave psychedelics legalization is not being accompanied by evidence-based regulation (15). Investment in psychedelics has increased considerably, with a number of psychedelics biotechnology and services companies listed on the US and Canadian public markets and the launch of the world's first psychedelics ETF (exchange traded fund) (16).

As compared to opioids, alcohol and tobacco, psychedelics have low addictive potential and benign toxicity profiles (1)(7). There is some evidence users experience reduced psychological distress and suicidality compared to users of other "recreational or illicit" drugs (17). Their perceived safety of psychedelics may be affirmed to some extent by their popular acceptance. Psychedelics are included within the broad category "hallucinogens" in the National Survey on Drug Use and Health (NSDUH), which collects lifetime, past-year and past month drug use estimates representative of persons aged 12 and over in each state and DC. The most recent survey data indicate a significant increase in hallucinogen use from 4.69 million to 6.01 million between 2015 and 2019. The increase was specific to LSD (60\% increase) and a $95 \%$ increase in other unspecified hallucinogens, a category that included the entheogens (i.e. psychoactive substances historically used for religious or spiritual purposes) peyote, mescaline and psilocybin, whereas PCP and ecstasy use declined over this period (18).

Psilocybin, which is the main psychoactive ingredient in more than 200 species of psychedelic mushrooms (PM) (19), has a particularly benign safety profile and possible positive health effects (20). It has been shown to be comparable to traditional selective serotonin reuptake inhibitors, serotonin-norepinephrine reuptake inhibitors in treating major depressive disorder under clinical trial conditions than (3)(21). Research into psilocybin and pain - a highly prevalent and serious health challenge in the US - is less far advanced, but no less appealing (7). Alongside this recent increase in information about promising therapeutic use the COVID-19 pandemic has imposed considerable societal stress, which adds to the propensity to self-medicate as a coping mechanism. This is manifest in the US with an increase in drinking and alcohol related harms (22), increased anxiety, depression, and social isolation among people with substance use disorders (23), and rising addiction rates associated with stress, personal loss and grief associated with the disease (24).

The purpose of this research was to ascertain knowledge about PM use and therapeutic need among American adults. We compared socio-demographic data for PM users and non-psychedelic users and explored the associations between PM use and various measures of health status, health related quality of life and self-reported mental health outcome measures. We also assessed whether two important contemporary events in the US that may have impacted on mental health, namely the COVID-19 pandemic and the national election and its aftermath, were associated with increased use. 


\section{METHODS}

\section{Data collection}

Data were collected through an on-line cross sectional survey of adults (18 years or older) residing in the US in accordance with Acumen Health Research Institute's (AHRI) established survey procedure. A random stratified sampling framework ensured a community-based sample with a demographic composition representative of the US adult population by region, gender, age, and race, according to the US Census and its standard classifications (US Census American Community Survey 5-year estimate, 2015-2019). Participants were recruited through AHRI's online research panels that were fielded monthly between November 2020 and March 2021, with each fielding lasting up to 7 days. The survey targeted approximately 1,000-2,000 respondents per month. We applied analysis weights to account for selection probabilities. Multiple quality control processes integrated throughout data collection, included digital finger printing technologies to validate unique respondents and to ensure study data was comprised of non-fraudulent responses. A detailed methodology has been published previously (25).

\section{Variables}

Participants reported on their individual demographic characteristics, educational attainment, health status and knowledge and use of psychedelics in the last 12 months. Estimated participant median household income was derived from US Census American Community Survey 5-year estimate 20152019 data for the participant's zip code. Self-reported co-morbidities were summarised according to the Charlson Comorbidity Index $(\mathrm{CCl})$, a survival stratification tool that assesses the comorbidity risk associated with several conditions and estimates 10-year survival in patients suffering from multiple comorbidities. $(26,27)$ Health-related quality of life (HRQoL) was assessed using the Veterans RAND 12-Item (VR-12) physical component summary (PCS), mental component summary (MCS), and health utility (VR-6D) (28). Anxiety was assessed with the Generalized Anxiety Disorder 7-item (GAD7) (29). Depression was assessed with the Patient Health Questionnaire 9-item (PHQ9) (30). A question about the positive uses of psilocybin "In the last 6 months I heard more than usual about the positive uses of psychedelic drugs (e.g., psychedelic mushrooms) for mental health issues (depression, PTSD, addiction, etc.)?" was rated on a 5-point Likert scale from 0 (strongly disagree) to 4 (strongly agree).

\section{Analysis}

Weighting was carried out according to the census data based on age, sex and region using a Taylor Series Linearization (TSL) method for estimating population characteristics controlling for complex sample survey data. PM users were compared with participants that had not taken a psychedelic in the past 12 months according to population level characteristics, views on psychedelics, treatments, co-morbidities and HRQoL. Users of other psychedelics and combined use of PMs and another psychedelic were excluded from the comparative analysis. An unweighted multivariate logistic regression model controlling for sex, age, race, region, education, employment, CCI score, GAD7, PHQ9 and health insurance predicted psilocybin use. Odds ratios (OR) with $95 \%$ confidence intervals are reported.

\section{Ethics}

Respondents were required to be 18 years old or older to participate in the study. Participants confirmed their voluntary agreement to participate and were informed they could leave the survey at any time. Each participant was compensated for their time spent participating according to a reward system based on marketplace points. Participants who fully completed our survey received points worth between $\$ 1.40$ and $\$ 2.45$. The actual amount of points awarded to each respondent was determined by the research panel's incentive policy.

The survey was deemed Institutional Review Board-exempt as all responses were anonymized, aggregated, and could not be related back to individual participants. 


\section{RESULTS}

A total of 7,139 participants were included in the sample - a response rate of $83.8 \%$. Psychedelic use in the last year was confirmed by 526 participants (or $7.4 \%$ of the total unweighted sample), which included 134 participants (3.8\%) who had used PMs and other psychedelics and $122(3.6 \%)$ who had used PMs exclusively. Weighted to the US adult population this represented $7.1 \%$ or $17,862,102$ adult psychedelic users overall (95\% Cl: $6.5-7.7)$, of which $49.2 \%$ or $8,780,328$ adults (95\% $\mathrm{Cl}: 44.7-53.6)$ were PM users.

We compared the 4,121,102 (1.7\%, 95\% Cl: 1.4-2.1) adults who used only PMs with $233,435,392$ (98.3\%, 95\% Cl: 97.9-98.6) adults who did not use any psychedelics. PM users were significantly more likely to be male (68.3\% [Cl: 59.3-76.1] compared to 47.2\% [Cl 45.9-48.5] among nonpsychedelic users), younger (mean age 38.1 vs 48.6 years), Hispanic/Latino (16.5\% vs $8.1 \%$ ) and reside in the US's Western Region (33.8\% vs $23.0 \%$ ). Other demographic and socio-economic measures such as income, employment and educational attainment were similar.

Table 1. Non-psychedelic user and PM user characteristics, US Adult population 2020/21 (weighted)

\begin{tabular}{|c|c|c|c|}
\hline & Sig. & $\begin{array}{l}\text { Non-psychedelic user } \\
(\mathrm{N}=233,435,392)\end{array}$ & PM user $(\mathrm{N}=4,121,102)$ \\
\hline \multicolumn{4}{|l|}{ Demographics } \\
\hline \multicolumn{4}{|l|}{ Sex } \\
\hline Female, \% (95\% Cl) & & $52.8(51.5-54.1)$ & $31.7(23.9-40.7)$ \\
\hline Male, \% $(95 \% \mathrm{Cl})$ & & $47.2(45.9-48.5)$ & $68.3(59.3-76.1)$ \\
\hline Age in years, mean (SD) & $\star \star \star \star$ & $48.56(16.60)$ & $38.12(10.83)$ \\
\hline \multicolumn{4}{|l|}{ Ethnicity } \\
\hline Black or African American, \% $(95 \% \mathrm{Cl})$ & & $11.5(10.8-12.2)$ & $9.6(5.8-15.6)$ \\
\hline White, \% (95\% Cl) & & $73.6(72.4-74.8)$ & $80.4(72.0-86.8)$ \\
\hline Other, \% $(95 \% \mathrm{Cl})^{\#}$ & & $14.9(13.8-16.0)$ & $10.0(5.3-18.0)$ \\
\hline Hispanic/Latino/Spanish origin, \% (95\% Cl) & ** & $8.1(7.4-8.9)$ & $16.5(10.6-24.7)$ \\
\hline \multicolumn{4}{|l|}{ Region } \\
\hline Northeast, \% (95\% Cl) & & $17.8(16.8-18.8)$ & $11.1(6.4-18.7)$ \\
\hline Midwest, \% (95\% Cl) & & $21.1(20.1-22.1)$ & $17.2(11.2-25.4)$ \\
\hline South, \% $(95 \% \mathrm{Cl})$ & & $38.1(36.9-39.4)$ & $37.9(29.5-47.1)$ \\
\hline West, \% (95\% Cl) & & $23.0(21.8-24.1)$ & $33.8(25.5-43.2)$ \\
\hline \multicolumn{4}{|l|}{$\underline{\text { Socioeconomics }}$} \\
\hline Education beyond high school, \% $(95 \% \mathrm{Cl})$ & & $73.4(72.3-74.5)$ & $80.4(72.2-86.6)$ \\
\hline Employed > 32 hours/week, \% $(95 \% \mathrm{Cl})$ & & $30.2(29.0-31.4)$ & $34.4(26.2-43.7)$ \\
\hline $\begin{array}{l}\text { Household income by area-level median, } \\
\text { mean (SD) }\end{array}$ & & $65,525(26,302)$ & $62,929(25,452)$ \\
\hline
\end{tabular}

Islander according to US Census classifications available at https://www.census.gov/topics/population/race/about.htm

In terms of health status (Table 2), PM users were significantly less likely to be overweight than nonusers, but reported significantly higher levels of certain comorbid conditions, namely depression, anxiety, migraines and insomnia. This was affirmed by quality of life measures for anxiety (GAD-7 score), and depression (PHQ-9 score). Overall quality of life (VR-12) was also lower for PM users as measured by lower mental health scores (39.5 vs 45.5$)$ and health utility ( 0.63 vs 0.69$)$, and higher 
medRxiv preprint doi: https://doi.org/10.1101/2021.09.20.21263824; this version posted September 22, 2021. The copyright holder for this preprint (which was not certified by peer review) is the author/funder, who has granted medRxiv a license to display the preprint in perpetuity.

It is made available under a CC-BY-NC-ND 4.0 International license .

levels of anxiety (GAD-7 scores of 9.6 vs 5.9) and depression (PHQ-9 scores of 11.2 vs 6.8) than non-users. They were also significantly more likely to report healthcare resource utilization, particularly urgent care (20.8\% vs $9.9 \%)$ and hospitalization $(9.2 \%$ vs $3.9 \%)$.

Table 2. Non-psychedelic user and PM user health, quality of life and health-seeking behaviour, US Adult population 2020/21 (weighted)

\begin{tabular}{|c|c|c|c|}
\hline & Sig. & $\begin{array}{l}\text { Non-psychedelic user } \\
(\mathrm{N}=233,435,392)\end{array}$ & $\begin{array}{l}\mathrm{PM} \text { user } \\
(\mathrm{N}=4,121,102)\end{array}$ \\
\hline \multicolumn{4}{|l|}{$\underline{\text { Health }}$} \\
\hline Body mass index (BMI) in lbs/in², mean (SD) & $* * *$ & $28.16(7.11)$ & $26.01(5.43)$ \\
\hline Comorbidities (total reported in past year), mean (SD) & & $4.07(3.66)$ & $4.20(3.10)$ \\
\hline \multicolumn{4}{|l|}{$\begin{array}{l}\text { Specific comorbid conditions experienced in past } \\
\text { year(1) }\end{array}$} \\
\hline Depression (self-reported), \% (95\% Cl) & $* * *$ & $28.3(27.2-29.5)$ & $56.8(47.5-65.7)$ \\
\hline Anxiety (self-reported), \% (95\% Cl) & *** & $32.8(31.6-34.0)$ & $49.1(40.0-58.3)$ \\
\hline $\begin{array}{l}\text { Chronic pain incl back, neck (self-reported), \% (95\% } \\
\mathrm{Cl} \text { ) }\end{array}$ & & $44.5(43.3-45.8)$ & $46.7(37.6-55.9)$ \\
\hline Allergies (self-reported), \% (95\% Cl) & & $28.7(27.6-29.9)$ & $32.2(24.3-41.1)$ \\
\hline Migraines (self-reported), \% (95\% Cl) & *** & $18.6(17.6-19.6)$ & $31.2(23.3-40.5)$ \\
\hline Insomnia (self-reported), \% (95\% Cl) & & $20.6(19.6-21.7)$ & $30.0(22.2-39.0)$ \\
\hline Hypertension (self-reported), \% (95\% Cl) & & $23.6(22.5-24.7)$ & $16.8(11.0-24.7)$ \\
\hline $\begin{array}{l}\text { Diarrhea, chronic, or more than occasional (self- } \\
\text { reported), \% }(95 \% \mathrm{Cl})\end{array}$ & & $14.2(13.3-15.1)$ & $10.7(6.3-17.5)$ \\
\hline Sleep apnea (self-reported), \% (95\% Cl) & & $8.2(7.5-8.9)$ & $10.1(5.8-17.1)$ \\
\hline GERD (self-reported), \% (95\% Cl) & & $13.6(12.7-14.5)$ & $9.7(5.3-16.9)$ \\
\hline $\begin{array}{l}\text { Constipation, chronic, or more than occasional (self- } \\
\text { reported), } \%(95 \% \mathrm{Cl})\end{array}$ & & $13.7(12.8-14.6)$ & $8.9(5.0-15.3)$ \\
\hline Hyperlipidemia (self-reported), \% $(95 \% \mathrm{Cl})$ & & $15.5(14.6-16.5)$ & $8.7(4.6-15.6)$ \\
\hline $\mathrm{CCl}$ score, mean (SD) & & $0.48(1.04)$ & $0.60(0.98)$ \\
\hline Anxiety (GAD-7 score), mean (SD) & $* * *$ & $5.88(5.79)$ & $9.62(5.76)$ \\
\hline Anxiety (GAD-7 $\geq 10), \%(95 \mathrm{Cl})$ & *** & $25.3(24.2-26.4)$ & $50.2(41.0-59.3)$ \\
\hline Depression (PHQ-9 score), mean (SD) & $* * *$ & $6.75(6.79)$ & $11.23(6.99)$ \\
\hline Depression (PHQ-9 $\geq 10), \%(95 \mathrm{Cl})$ & $* \star \star$ & $29.5(28.4-30.7)$ & $56.1(46.6-65.0)$ \\
\hline \multicolumn{4}{|l|}{$\underline{\text { Quality of life }}$} \\
\hline \multicolumn{4}{|l|}{ VR-12 } \\
\hline MCS, mean (SD) (t-score) & *** & $45.53(12.44)$ & $39.49(11.25)$ \\
\hline PCS, mean (SD) (t-score) & 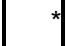 & $45.28(10.45)$ & $43.51(9.24)$ \\
\hline Health utility (VR-6D), mean (SD) & *** & $0.69(0.12)$ & $0.63(0.10)$ \\
\hline \multicolumn{4}{|l|}{$\underline{\text { Health-seeking behaviour }}$} \\
\hline Primary care physician visit, \% $(95 \% \mathrm{Cl})$ & & $52.4(51.1-53.7)$ & $51.1(41.9-60.3)$ \\
\hline Specialist, \% (95\% Cl) & & $28.6(27.5-29.8)$ & $23.2(16.4-31.7)$ \\
\hline
\end{tabular}




\begin{tabular}{|l|r|r|r|}
\hline Other healthcare provider, \% $(95 \% \mathrm{Cl})$ & $*$ & $19.7(18.7-20.7)$ & $28.2(20.7-37.1)$ \\
\hline Urgent care, \% $(95 \% \mathrm{Cl})$ & $* * *$ & $9.9(9.2-10.7)$ & $20.8(14.3-29.3)$ \\
\hline Outpatient procedure or surgery, \% $(95 \% \mathrm{Cl})$ & & $8.6(7.9-9.3)$ & $7.2(3.5-14.2)$ \\
\hline Emergency department, \% $(95 \% \mathrm{Cl})$ & & $10.1(9.4-10.9)$ & $12.9(8.1-20.1)$ \\
\hline Hospitalization, \% (95\% Cl) & $* *$ & $3.9(3.4-4.4)$ & $9.2(5.2-15.8)$ \\
\hline
\end{tabular}

${ }^{*} p<0.05 ;{ }^{* *} p<0.01 ;{ }^{* * *} p \leq 0.001$

(1) Co-morbid conditions are shown for the 10 most reported conditions for each cohort.

PM users consistently and significantly held more favorable views of the positive potential for PM use for the treatment of a range of conditions than non-users (Table 3), including for general mental health, well-being and personal development ( $65.8 \%$ vs $15.8 \%)$, and managing diagnosed $(50.9 \%$ vs $16.6 \%$ ) and self-diagnosed psychiatric conditions (34.7\% vs $7.6 \%$ ). This was consistent with their rationale for using PMs, with general mental health and well-being being the most common (63.6\%), followed by use for diagnosed psychiatric conditions (31.8\%) and self-diagnosed conditions (19.0\%). PM users were also significantly more likely than non-users to have heard more frequent positive reporting of the use of psychedelic drugs for mental health issues (depression, PTSD, addiction, etc.) in the last six months than previously (mean score 2.06 vs 3.56 out of a scale of 1 "strongly agree" to 5 "strongly disagree"). Frequency of use did not seem to have been influenced on account of either COVID-19 or election politics. PM use was significantly associated with medical treatment following use $(17.9 \%$ of users).

Table 3. Non-psychedelic user and PM user, knowledge and use of PMs for health and wellbeing, US Adult population 2020/21 (weighted)

\begin{tabular}{|c|c|c|c|}
\hline & Sig. & $\begin{array}{l}\text { Non-psychedelic user } \\
(\mathrm{N}=233,435,392)\end{array}$ & $\begin{array}{l}\mathrm{PM} \text { user } \\
(\mathrm{N}=4,121,102)\end{array}$ \\
\hline \multicolumn{4}{|l|}{ Health and wellbeing knowledge } \\
\hline $\begin{array}{l}\text { More frequent positive information about PM use for mental } \\
\text { health in last } 6 \text { months (score)(range:1, strongly agree to } 5 \text {, } \\
\text { strongly disagree), mean (SD) }\end{array}$ & *** & $3.56(1.20)$ & $2.06(1.07)$ \\
\hline $\begin{array}{l}\text { Positive potential for general mental health, well-being and } \\
\text { personal development (preventive) } \%(95 \% \mathrm{Cl})\end{array}$ & $* * *$ & $15.8(14.9-16.7)$ & $65.8(56.7-73.9)$ \\
\hline $\begin{array}{l}\text { Positive potential managing a diagnosed psychiatric condition - } \\
\text { PTSD, depression, addiction, etc (curative), \% }(95 \% \mathrm{Cl})\end{array}$ & $\star \star \star \star *$ & $16.6(15.7-17.6)$ & $50.9(41.7-60.1)$ \\
\hline $\begin{array}{l}\text { Positive potential managing a self-diagnosed condition/concern } \\
\text { - relationship issue, bereavement, trauma, addiction, etc } \\
\text { (curative), \% }(95 \% \mathrm{Cl})\end{array}$ & *** & $7.6(7.0-8.3)$ & $34.7(26.5-44.0)$ \\
\hline No knowledge, \% $(95 \% \mathrm{Cl})$ & 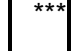 & $69.7(68.8-70.9)$ & $13.6(8.3-21.4)$ \\
\hline \multicolumn{4}{|l|}{ Reasons for use } \\
\hline $\begin{array}{l}\text { General mental health, well-being and personal development } \\
\text { (preventive), \% (95\% Cl) }\end{array}$ & -1 & -1 & $63.6(54.2-72.0)$ \\
\hline $\begin{array}{l}\text { Managing a diagnosed psychiatric condition - PTSD, } \\
\text { depression, addiction, etc (curative), \% }(95 \% \mathrm{Cl})\end{array}$ & -1 & -1 & \\
\hline $\begin{array}{l}\text { Managing a self-diagnosed condition/concern - relationship } \\
\text { issue, bereavement, trauma, addiction, etc (curative), \% (95\% } \\
\text { CI) }\end{array}$ & -1 & -1 & $19.0(13.0-27.0)$ \\
\hline \multicolumn{4}{|l|}{$\underline{\text { Frequency of use }}$} \\
\hline Increased on account of COVID-19 & -1 & -1 & $14.7(9.4-22.3)$ \\
\hline Decreased on account of COVID-19 & -1 & -1 & $17.9(11.9-25.9)$ \\
\hline No impact & -1 & -1 & $66.6(57.5-74.7)$ \\
\hline Increased on account of election politics & -1 & -1 & $13.1(8.1-20.5)$ \\
\hline
\end{tabular}




\begin{tabular}{|c|c|c|}
\hline Decreased on account of election politics & -1 & $11.6(7.0-18.7)$ \\
\hline No impact & - & $74.3(65.5-81.5)$ \\
\hline \multicolumn{3}{|l|}{ Potential harm } \\
\hline Seeking medical treatment following use & -1 & $17.9(11.9-26.0)$ \\
\hline
\end{tabular}

The multivariate logistic regression analysis explored the correlation between various factors and PM use (Table 4). Factors predictive of PM use included being male [OR=1.53 (1.09-2.15)] and reporting worse health [OR=1.42 (1.22-1.65)]. Those with health insurance [OR=0.50 $(0.35-0.72)]$, increased age $[\mathrm{OR}=0.92(0.90-0.93)]$, and relative to those living in the west US census region, those living in the northeast [OR=0.27 (0.15-0.50)], midwest [OR=0.34 (0.20-0.56)], and south [OR=0.38 (0.260.55)] were less likely to report PM use.

\section{[[[[Figure 1. Here]]]}

Figure 1. Results of multivariate logistic regression model predicting past year psychedelic mushroom use for selected demographic and educational factors and health and comorbidity indicators

\section{DISCUSSION}

The objective of the present analysis was to ascertain knowledge about PMs among American adults and explore associations between PM use and various general and self-reported mental health outcome measures. Our findings confirm the popularity of psychedelics more broadly and PMs specifically among the US adult population (19,31,32). Estimated past-year psychedelic use of $7,7 \%$, which equated to approximately 17,9 million adult Americans (95\% Cl: $16.4-19,4$ million) was almost three times higher than recorded in the NSDUH, which estimated past-year hallucinogen use at just more than 6 million persons in 2019. Similarly estimated past-year PM use of 4.1 million adult Americans (95\% Cl: $3.4-5.1$ million) was also significantly higher than the $2019 \mathrm{NSDUH}$, which reported past year use of all hallucinogens other than $L S D, P C P$ and ecstasy at less than 1 million persons (18).

The popularity of PMs amongst psychedelic users, approximately half of all past year psychedelic use in our study, was not unexpected. Psilocybin has a relatively benign reputation among psychedelics generally, which is further enhanced by PMs being a natural rather than synthetic source of psilocybin. Among the different classes of psychedelics, classic tryptamines, which include psilocybin, are uniquely associated with a decreased likelihood of psychological distress and suicidal thinking and are widely considered to hold the greatest therapeutic potential among lifetime users(33). This was confirmed by PM users identified in our study. Despite this favourable view we found concerning associations between of PM use and negative mental health outcomes including anxiety, depression, comorbidities and medical treatment following use. Although associations for anxiety and depression were not significantly associated with PM use in the logistic regression analysis, PM users were still significantly associated with comorbidities and were less likely to have health insurance. Higher utilization of healthcare resources could increase costs and, in turn, drive a gap in care for PM users.

These findings were distinctly different from a recent international study which showed that regular users of psychedelic drugs had less psychological stress compared to occasional users and nonusers, suggesting that the use of psychedelics might either be a protective factor or that people with certain traits were more prone to frequently use psychedelic drugs (34). This difference could either be ascribed to our study focusing on any use rather than regular use, or that PM users in the US comprise a distinctly different demographic grouping than their international counterparts.

Either way, more certainty is needed about dosage and treatment effect windows for PMs, as well as the potential addictive effects and side effects of consistent use arising from interactions of psilocybin 
It is made available under a CC-BY-NC-ND 4.0 International license .

with dopamine and dopamine receptors (35), as psilocybin stimulates dopamine receptors indirectly (1). Ongoing litigation of pharmaceutical companies implicated in the opioid epidemic in the US (36) emphasises the importance of a considered approach in developing a comprehensive understanding of risks and benefits not only to individual users, but also for their families and communities.

While use of PMs may have been expected to increase during the COVID-19, as individuals seek to self-medicate to deal with the trauma of isolation and anxiety about the virus (37), interest is unlikely to wane in its aftermath. COVID-19 has thrown mental health disorders into sharp focus and therapeutic interventions are likely to find renewed impetus. Almost one-third of COVID-19 cases with serious complications may experience PTSD (38) while the full impact on grieving families and communities will only become apparent in the future. However, the overwhelmingly positive coverage of psychedelics requires some circumspection and some of the correlates of LSD use serve as a warning. These include higher levels of antisocial behavior as measured through interaction with the criminal justice system and the presence of comorbid mental health and substance abuse disorders. (39).

Classical serotonergic psychedelics do not cause neurotoxic effects, organ damage or long-term neuropsychological deficits (1). Acute psychological effects remain a possibility, but these can be averted through supervised administration of perception-altering doses and there are also distinct medicinal uses of sub-perceptual doses or molecules lacking perceptual effects (40). There is also limited possibility of physical dependence. Animal studies have shown that they lack reinforcing properties that induce self-administration, which limits the potential for abuse as well as withdrawal symptoms $(41,42)$. This is consistent with a US population-based study that indicated no association between lifetime use of psychedelics generally, or specific psychedelics including psilocybin, and increased rate of mental illness and prolonged, or re-occurring, perceptual effects(43).

Less information is available for novel psychedelics, which are becoming increasingly popular and seem less benign. Sexton et al. (2019) found a greater likelihood of past year suicidal thinking and past year suicidal planning among lifetime users of novel psychedelics (44). Subsequent analysis of the NSDUH found that novel phenethylamine specifically was associated with increased suicidal thinking and suicidal planning (33).

Across cultures, people try to make sense of the world around them, including how likely it is that a negative outcome will occur for them and what will increase or reduce that risk - lay epidemiology (45). Their decisions are complicated not only by the expanding variety of available psychedelics, but also their potential application for an increasing range of therapeutic uses. It is known, for example, that psychedelics exert significant modulatory effects on immune responses by altering signalling pathways involved in inflammation, cellular proliferation, and cell survival (46). Preclinical research has shown that psychedelics promote structural and functional neural plasticity in key brain regions linked to psychological functioning (9). A recent milestone publication provides the scientific hypothesis for low doses of psychedelics exerting effects on mental well-being and neurological healing through indirect modulation of the gut-brain axis (47). Consequently, therapies involving psychedelics are among the innovative treatments for traumatic brain injury (48).

Population-based research such as the present study could help to indicate receptivity for possible therapeutic application. In addition it can be argued that there is a need for such data to supplement traditional confirmatory with real world evidence and studies that can inform pragmatic trial designs (3). For example the recently reported association between lifetime classic psychedelic use and cardiometabolic diseases (32) would be strengthened if the association was found to be consistent when measured against more recent use.

Our study design presented both strengths and limitations. The use of an online data collection platform reduced the risk of stigma by ensuring privacy and confidentiality, which may explain the considerably higher past year estimates than were reported in other surveys. Although we made every effort to avoid sampling biases and to ensure the validity of information, standard survey limitations arising from self-reporting still applied and may have been amplified by including only respondents who had access to a computer and were willing to take an online survey. Another limitation was that comparisons were made with no alpha adjustment resulting in an increased risk of Type 1 errors. We excluded users of other psychedelics and users that combined PM use with use of 
other psychedelic to avoid confounding, but in so doing may have missed other significant associations. The inability to distinguish between different users may have introduced some selection bias - people using psychedelics parsimoniously for the first time were more likely to be included, whereas experienced "psychonauts" using a wide range of designer psychedelics could have been excluded (49). We also note that the timing of the study was unusual, in that it was conducted at the height of the COVID-19 pandemic, which may make the findings less generalisable to surrounding time periods. In its favour, questions about recent rather than lifetime PM use present information that is current and arguably more relevant for a public health response.

\section{CONCLUSIONS}

The present research clearly demonstrates the utility of population-based understanding of entheogen use, among which PMs remain particularly popular. Despite the overwhelmingly positive reputation of life time use of PMs conferring protective qualities our study has shown a disturbing association with negative physiological and mental health outcomes. The extent to which uptake is influenced by emerging scientific evidence versus anecdotal or pseudoscientific knowledge remains unclear, but is incidental to the need for the development of guidelines to optimize therapeutic use. Future research should include regularized application of our population-level methodology surveys to assess changes over time as well as additional modules to identify key drivers of use and misuse for different entheogens, and to indicate possible therapeutic applications for specific conditions. Separate analysis of other psychedelic use, exclusively and in combination, should also be considered.

\section{Author Contributions}

Richard $\mathrm{M}$ was the primary author who drafted the manuscript summarizing the findings. Rob $\mathrm{M}$ and AM informed methodology, conducted analyses and were responsible for ensuring analyses were interpreted correctly. LL, corresponding author, conceptualised the study and, along with BL, contributed meaningful pharmacological expertise to aid in the interpretation of results. All authors contributed to and approved of the final version of the manuscript.

\section{Funding}

BYAS sponsored Back of the Yards Algae Sciences, Chicago-based sustainable biotechnology company.

\section{REFERENCES}

1. Nichols DE. Psychedelics. Pharmacol Rev (2016) 68:264-355. doi:10.1124/pr.115.011478

2. Nutt D, Carhart-Harris R. The Current Status of Psychedelics in Psychiatry. JAMA Psychiatry (2021) 78:121. doi:10.1001/jamapsychiatry.2020.2171

3. Carhart-Harris R, Giribaldi B, Watts R, Baker-Jones M, Murphy-Beiner A, Murphy R, Martell J, Blemings A, Erritzoe D, Nutt DJ. Trial of Psilocybin versus Escitalopram for Depression. $N$ Engl J Med (2021) 384:1402-1411. doi:10.1056/NEJMoa2032994

4. Reiff CM, Richman EE, Nemeroff CB, Carpenter LL, Widge AS, Rodriguez Cl, Kalin NH, McDonald WM. Psychedelics and psychedelic-assisted psychotherapy. Am J Psychiatry (2020) 177:391-410. doi:10.1176/appi.ajp.2019.19010035

5. Andersen KAA, Carhart-Harris R, Nutt DJ, Erritzoe D. Therapeutic effects of classic serotonergic psychedelics: A systematic review of modern-era clinical studies. Acta Psychiatr Scand (2021) 143:101-118. doi:10.1111/acps.13249 
6. Romeo B, Karila L, Martelli C, Benyamina A. Efficacy of psychedelic treatments on depressive symptoms: A meta-analysis. J Psychopharmacol (2020) 34:1079-1085. doi:10.1177/0269881120919957

7. Castellanos JP, Woolley C, Bruno KA, Zeidan F, Halberstadt A, Furnish T. Chronic pain and psychedelics: a review and proposed mechanism of action. Reg Anesth Pain Med (2020) 45:486-494. doi:10.1136/rapm-2020-101273

8. Siegel AN, Meshkat S, Benitah K, Lipsitz O, Gill H, Lui LMW, Teopiz KM, McIntyre RS, Rosenblat JD. Registered clinical studies investigating psychedelic drugs for psychiatric disorders. J Psychiatr Res (2021) 139:71-81. doi:10.1016/j.jpsychires.2021.05.019

9. Ly C, Greb AC, Cameron LP, Wong JM, Barragan E V., Wilson PC, Burbach KF, Soltanzadeh Zarandi S, Sood A, Paddy MR, et al. Psychedelics promote structural and functional neural plasticity. Cell Rep (2018) 23:3170-3182. doi:10.1016/j.celrep.2018.05.022

10. Elflein J. Psychedelic therapy-Statistics \& Facts. (2018) Available at: https://www.statista.com/topics/4277/psychedelic-therapy/ [Accessed March 23, 2021]

11. Jacobs BA. The Psychedelic Revolution Is Coming. Psychiatry May Never Be the Same. New York Times (2021)1-12. Available at:

https://www.nytimes.com/2021/05/09/health/psychedelics-mdma-psilocybin-molly-mentalhealth.html

12. Mitchell JM, Bogenschutz M, Lilienstein A, Harrison C, Kleiman S, Parker-Guilbert K, Ot'alora G M, Garas W, Paleos C, Gorman I, et al. MDMA-assisted therapy for severe PTSD: a randomized, double-blind, placebo-controlled phase 3 study. Nat Med (2021) doi:10.1038/s41591-021-01336-3

13. What We Know about Psychedelics and Healing, So Far.1-14. Available at: https://goop.com/psychedelics-and-healing/

14. Woolfe S. The Growth of Psychedelic Content on Clubhouse. (2021)1-11. Available at: https://psychedelicinvest.com/the-growth-of-psychedelic-content-on-clubhouse/

15. Smith WR, Appelbaum PS. Two Models of Legalization of Psychedelic Substances. Jama (2021)1-2. doi:10.1001/jama.2021.12481

16. Blum J. The Psychedelic Renaissance Is Here - And The US Needs It Desperately. (2021)110. Available at: https://medium.com/invisible-illness/the-psychedelic-renaissance-is-here-andthe-us-needs-it-desperately-f2328de446a2

17. Hendricks PS, Thorne CB, Clark CB, Coombs DW, Johnson MW. Classic psychedelic use is associated with reduced psychological distress and suicidality in the United States adult population. J Psychopharmacol (2015) 29:280-288. doi:10.1177/0269881114565653

18. Substance Abuse and Mental Health Services Administration. 2019 National Survey on Drug Use and Health. Available at: https://www.samhsa.gov/data/report/2019-nsduh-detailed-tables [Accessed August 24, 2021]

19. Yockey A, King K. Use of psilocybin ("mushrooms") among US adults: 2015-2018. J Psychedelic Stud (2021)2015-2018. doi:10.1556/2054.2020.00159

20. Hendricks PS, Johnson MW, Griffiths RR. Psilocybin, psychological distress, and suicidality. $J$ Psychopharmacol (2015) 29:1041-1043. doi:10.1177/0269881115598338

21. Davis AK, Barrett FS, May DG, Cosimano MP, Sepeda ND, Johnson MW, Finan PH, Griffiths RR. Effects of Psilocybin-Assisted Therapy on Major Depressive Disorder: A Randomized Clinical Trial. JAMA Psychiatry (2021) 78:481-489. doi:10.1001/jamapsychiatry.2020.3285

22. Rubin R. Alcohol-Related Diseases Increased as Some People Drank More During the COVID-19 Pandemic. (2021)1-3.

23. Englander H, Salisbury-Afshar E, Gregg J, Martin M, Snyder H, Weinstein Z, King C. Converging crises: Caring for hospitalized adults with substance use disorder in the time of covid-19. J Hosp Med (2020) 15:628-630. doi:10.12788/JHM.3485

24. Koob GF, Powell P, White A. Addiction as a Coping Response: Hyperkatifeia, Deaths of Despair, and COVID-19. Am J Psychiatry (2020) 177:1031-1037.

doi:10.1176/appi.ajp.2020.20091375 
It is made available under a CC-BY-NC-ND 4.0 International license .

25. Morlock R, Morlock A, Downen M, Shah SN. COVID-19 prevalence and predictors in United States adults during peak stay-at-home orders. PLoS One (2021) 16:1-12. doi:10.1371/journal.pone.0245586

26. Charlson ME, Pompei P, Ales KL, MacKenzie CR. A new method of classifying prognostic comorbidity in longitudinal studies: Development and validation. J Chronic Dis (1987) 40:373383. doi:10.1016/0021-9681(87)90171-8

27. Charlson M, Szatrowski TP, Peterson J, Gold J. Validation of a combined comorbidity index. J Clin Epidemiol (1994) 47:1245-1251. doi:10.1016/0895-4356(94)90129-5

28. Iqbal S, Rogers W, Selim A, Qian S, Lee A, Ren X, Rothendler J, Miller D, Kazis L. The veterans RAND 12 item health suvery (VR-12): what it is and how it is used. Bedford, MA, USA. (2007).

29. Spitzer RL, Kroenke K, Williams JBW, Löwe B. A brief measure for assessing generalized anxiety disorder: The GAD-7. Arch Intern Med (2006) 166:1092-1097.

doi:10.1001/archinte.166.10.1092

30. Kroenke K, Spitzer RL, Williams JBW. The PHQ-9: Validity of a brief depression severity measure. J Gen Intern Med (2001) 16:606-613. doi:10.1046/j.1525-1497.2001.016009606.x

31. Frohe T, Beseler CL, Mendoza AM, Cottler LB, Leeman RF. Perceived health, medical, and psychiatric conditions in individual and dual-use of marijuana and nonprescription opioids. $J$ Consult Clin Psychol (2019) 87:859-871. doi:10.1037/ccp0000431

32. Simonsson O, Sexton JD, Hendricks PS. Associations between lifetime classic psychedelic use and markers of physical health. J Psychopharmacol (2021) 35:447-452. doi:10.1177/0269881121996863

33. Sexton JD, Nichols CD, Hendricks PS. Population Survey Data Informing the Therapeutic Potential of Classic and Novel Phenethylamine, Tryptamine, and Lysergamide Psychedelics. Front Psychiatry (2020) 10:3389. doi:10.3389/fpsyt.2019.00896

34. Révész D, Ona G, Rossi GN, Rocha JM, dos Santos RG, Hallak JEC, Alcázar-Córcoles MÁ, Bouso JC. Cross-Sectional Associations Between Lifetime Use of Psychedelic Drugs and Psychometric Measures During the COVID-19 Confinement: A Transcultural Study. Front Psychiatry (2021) 12:1-14. doi:10.3389/fpsyt.2021.687546

35. Mukhdomi T, Mukhdomi J. Chronic pain and psychedelics: proceeding with caution. Reg Anesth \&amp;amp; Pain Med (2020)rapm-2020-101994. doi:10.1136/rapm-2020-101994

36. McGreal C. Big pharma executives mocked ' pillbillies ' in emails, West Virginia opioid trial hears. Guard (2021)1-5. Available at: https://www.theguardian.com/usnews/2021/may/16/amerisourcebergen-pillbillies-emails-west-virginia-opioid-trial-

37. Chiappini S, Guirguis A, John A, Corkery JM, Schifano F. COVID-19: The Hidden Impact on Mental Health and Drug Addiction. Front Psychiatry (2020) 11:10-13. doi:10.3389/fpsyt.2020.00767

38. Janiri D, Carfì A, Kotzalidis GD, Bernabei R, Landi F, Sani G. Posttraumatic Stress Disorder in Patients After Severe COVID-19 Infection. JAMA Psychiatry (2021) 78:567. doi:10.1001/jamapsychiatry.2021.0109

39. Killion B, Hang A, Alsolami A, Vaughn MG, Oh PS, Salas-wright CP. LSD use in the United States $\exists$ : Trends , correlates, and a typology of us. Drug Alcohol Depend (2021) 223:108715. doi:10.1016/j.drugalcdep.2021.108715

40. Johnson M, Richards W, Griffiths R. Human hallucinogen research: guidelines for safety. J Psychopharmacol (2008) 22:603-620. doi:10.1177/0269881108093587

41. Halberstadt AL, Geyer MA. "Effect of Hallucinogens on Unconditioned Behavior," in Brain Imaging in Behavioral Neuroscience, 159-199. doi:10.1007/7854_2016_466

42. Johnson MW, Griffiths RR, Hendricks PS, Henningfield JE. The abuse potential of medical psilocybin according to the 8 factors of the Controlled Substances Act. Neuropharmacology (2018) 142:143-166. doi:10.1016/j.neuropharm.2018.05.012

43. Krebs TS, Johansen PØ. Psychedelics and mental health: a population study. PLoS One (2013) 8: doi:10.1371/journal.pone.0063972 
medRxiv preprint doi: https://doi.org/10.1101/2021.09.20.21263824; this version posted September 22, 2021. The copyright holder for this preprint (which was not certified by peer review) is the author/funder, who has granted medRxiv a license to display the preprint in perpetuity.

It is made available under a CC-BY-NC-ND 4.0 International license .

44. Sexton JD, Crawford MS, Sweat NW, Varley A, Green EE, Hendricks PS. Prevalence and epidemiological associates of novel psychedelic use in the United States adult population. $J$ Psychopharmacol (2019) 33:1058-1067. doi:10.1177/0269881119827796

45. Frankel S, Davison C, Smith GD. Lay epidemiology and the rationality of responses to health education. Br J Gen Pract (1991) 41:428-430.

46. Szabo A. Psychedelics and immunomodulation: Novel approaches and therapeutic opportunities. Front Immunol (2015) 6:1-11. doi:10.3389/fimmu.2015.00358

47. Kuypers KPC. Psychedelic medicine: The biology underlying the persisting psychedelic effects. Med Hypotheses (2019) 125:21-24. doi:10.1016/j.mehy.2019.02.029

48. Siebert A. From NHL enforcer to $\mathrm{CEO} \sqsupset$ : Daniel Carcillo's new company wants to treat traumatic brain injury with psilocybin. Forbes (2021)1-6. Available at:

https://www.forbes.com/sites/amandasiebert/2021/01/22/from-nhl-enforcer-to-ceo-danielcarcillos-new-company-wants-to-treat-traumatic-brain-injury-withpsilocybin/?sh=2d1136181af6

49. Catalani V, Corkery JM, Guirguis A, Napoletano F, Arillotta D, Zangani C, Vento A, Schifano F. Psychonauts' psychedelics: A systematic, multilingual, web-crawling exercise. Eur Neuropsychopharmacol (2021) 49:69-92. doi:10.1016/j.euroneuro.2021.03.006 
Predictive of Predictive of

Factor OR $(95 \% \mathrm{CI})$

$\begin{aligned} \text { Male } & 1.53(1.09-2.15) \\ \text { Age } & 0.92(0.90-0.93) \\ \text { White } & 1.20(0.83-1.74) \\ \text { Northeast } & 0.27(0.15-0.50) \\ \text { Midwest } & 0.34(0.20-0.56) \\ \text { South } & 0.38(0.26-0.55)\end{aligned}$

Education more than high school Employed more than 32 hours $1.22(0.83-1.79)$ 0.94 (0.64-1.39) 1.42 (1.22-1.65) 1.27 (0.80-1.99) $1.15(0.73-1.79)$ $0.50(0.35-0.72)$ non-psychedelic use psychedelic mushroom use

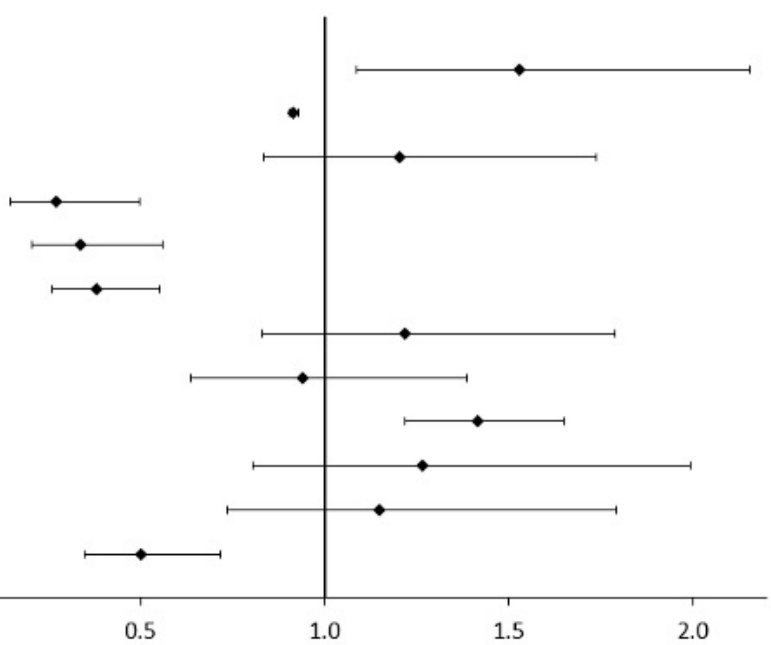

Odds ratio (OR), $95 \%$ Confidence interval (CI) 